\title{
Achieving engagement in injury and violence prevention research
}

\author{
Jennifer Woody Collins ${ }^{\oplus 1,2}$
}

\begin{abstract}
'School of Communication Studies, Ohio University, Athens, Ohio, USA

${ }^{2}$ Injury Prevention Research

Center, Univerity of North

Carolina, Chapel Hill, NC, United

States
\end{abstract}

\section{Correspondence to}

Ms Jennifer Woody Collins,

Communication Studies, Ohio University, Athens, $\mathrm{OH} 45701$

USA; jennifer.e.woody@gmail. com

Received 18 June 2019

Revised 11 July 2019

Accepted 13 July 2019

Published Online First

12 August 2019

Check for updates

(C) Author(s) (or their employer(s)) 2019. No commercial re-use. See rights and permissions. Published by BMJ.

To cite: Woody Collins J. Inj Prev 2019:25:472-475.

\section{ABSTRACT}

This paper examines the idea of engaged research and the ways it is conceived and applied in injury and violence prevention. To achieve meaningful engagement, I argue that efforts should be directed to relationships with the people who will be impacted by injury prevention interventions rather than to professional practitioners. Additionally, I call for researchers to avoid predefining injury problems prior to engaging with the people it is intended to affect. Prefiguring problems circumscribes the possibilities for engagement with individuals who do not value risk as a determining factor in problem definition and cuts off and devalues other ways of knowing.

Recently, a discussion around the need for more engaged scholarship has emerged within injury and violence prevention as a way to achieve several long-desired goals, notably better translation, uptake, and usefulness for injury research findings and their potential to improve health, safety and quality of life. However, there is a need for a more in-depth examination of the intent, methods and underlying assumptions of engaged research because approaches to engagement are differentially applied and understood across the field. As it is now, conceptions of engagement are headed towards potentially reifying hierarchies of knowledge that place scientific research in a more lofty and respected position than lay public, patient or otherwise 'non-expert' ways of knowing. I assert that even while various publics are 'engaged' in the conduct of research for injury prevention, these relationships retain the imbalance prevalent in expert/ non-expert interactions. To better understand how scientific knowledge is overvalued in engaged relationships, we need to identify and reveal the underlying logics of these interactions as a step towards a more genuinely equal exchange.

To look at some of the pitfalls in the current ways engaged research is conceptualised, I will lay out two arguments. First, there is a need to better define who is involved in the engagement of engaged research. Engagement has different purposes and can achieve different ends depending on who is involved, but there is a tendency in injury research to talk about heterogeneous groups such as non-academics, practitioners and communities as if they are interchangeable with one another. Engagement should prioritise locating and drawing out the diverse, conflicting perspectives that are held by the people who will be most impacted by researchbased interventions. I argue that community members can provide these perspectives more fully than professional staff in community-based organisations. Second, I will examine how scientific ways of knowing dominate engaged research activities by predefining injury problems before other perspectives are included. In this line of argument, I offer examples for how and why predetermined scientific frames impede fully engaged research. In both of these discussions, the goal is to interrogate the idea of engagement in hopes of achieving more equitable, democratic, and just approaches to preventing injuries and violence.

\section{COMPLICATING COMMUNITY AND PARSING OUT PRACTICE}

When considering engagement, there needs to be a more precise definition of who is included in the relationship and for what purpose. Currently, the rhetoric around engagement conflates all 'non-academics' such as practitioners and communities into one group, and the lumping of these categories creates a situation where engagement can be claimed even when it is not inclusive of the people who will be impacted by injury prevention programmes. Often in engaged injury prevention research, practice engagement has signified working with professional organisational representatives who themselves have a level of expertise that is more characterised by academic rather than experiential knowledge. When researchers partner with organisations, such as staff at a hospital or health department, and consider that engaged research, they have fallen short of their goal if they are seeking a participatory process that involves people who will be affected by the programme being developed. For instance, in the case studies showing successful examples of 'academic-practitioner collaboration' presented by Smith et al, ${ }^{1}$ two of the examples involved university researchers working with state health department partners. While the input of the state health department representatives was indeed considered in the design of interventions, the voices of the people on the receiving end of programmes and services were absent. Claiming engagement after consulting organisational representatives shows how communities and practitioners are viewed as an undifferentiated unit. Practitioners have different values, goals and knowledge than people living in communities that will have to live with the effects of interventions developed on their behalf. Engagement should only be claimed when researchers involve the people impacted by the proposed intervention. 
The thinking behind engagement with representatives from professional organisations is that these groups are somehow 'closer' to communities, both in physical location and in understanding the values that are important within a group of people. In this positioning, entities such as hospitals or health departments are thought to sufficiently represent 'the community perspective'. However, professionalised groups are actually practising what Dempsey has named communicative labour, where they are "representing and speaking on the behalf of marginalised groups" (p.328). ${ }^{2}$ Communicating about and on behalf of people in communities is a standard and underexamined practice of professional local governmental and non-profit health organisations. Despite how common communicative labour is, practice should not be considered a valid stand-in for meaningful engagement with community perspectives. Professional organisations are in a position that requires the negotiation of competing needs and values among their organisational priorities, answering to the demands and interests of funders, as well as the concerns of community members. To maintain viability, often organisations enact programmes based on requirements from funders rather than prioritising community needs. This common situation demonstrates how practice is not actually able to fully honour community values. Professionals in local health-focused organisations are rightly and logically proponents of their own needs and interests, but this makes them unable to represent the people who are directly affected by injury prevention interventions.

As we move away from relying on professional practitioners serving as representatives of community voice, the difficulties of locating and knowing the diverse, conflicting and disparate ideas held by a 'community' quickly become apparent. Existing systems for engagement including town hall meetings, online surveys and other methods that are heavily reliant on individuals having a mastery of rational argumentation as well as proficiency in writing, reading and speaking cannot continue to be used if meaningful engagement is the goal. The most marginalised groups in any community are frequently the ones barred from decision-making spaces, yet are also habitually the focus of interventions. If engagement seeks to consider the voices of people who will experience the impacts of interventions designed to address injury and violence problems, injury research needs to reconsider whose voices are included and in what ways they are invited into the discussion.

The case of a Falls Prevention Coalition in the Southern United States can help illustrate the problem with relying on professional practitioners to determine the appropriateness of an injury prevention intervention. The community-based falls prevention professionals at the local hospital were interested in offering evidence-based falls prevention programming for members of their community and were introduced to the CDC's Tai Chi programme. Typically, this would be considered a win for public health since it involved the implementation of an evidence-based programme. However, when presenting Tai Chi to local community residents, some did not want to participate. A segment of the community associated Tai Chi with Japan, a country some older adults held a prejudice against due to animosity held over from World War II, and Pearl Harbor in particular. Researchers at the $\mathrm{CDC}$ and professional health educators within the hospital had no frame of reference to know that this would be a barrier to participation in the Tai Chi programme. However, engaged research, in the sense of participation from the individuals receiving the programme, could have avoided this scenario had it not relied only on professional organisational representatives as knowledge holders.
This example also draws out the difficulty of listening to community voices when the perspectives presented are seemingly unrelated to the issue at hand and clearly outside of the realm of what is considered 'rational' thought within scientific circles. Opening science up to ways of knowing outside of what is considered to be reasonable, logical and sound is a part of engaged research that can challenge deeply held scientific values, making it a practice that should be entered into with awareness and openness. Noticing any judgements about the information coming from non-health professional individuals in communities is an important way to begin seeing how different ways of knowing are unintentionally left out of decision-making processes. Extending on the discussion of meaningful inclusion of the diverse knowledge found in communities, I now turn to the problem of predetermined frames that shape what can be used to understand injury issues.

\section{PREFIGURED PROBLEMS}

Stemming from the work of Wynne, ${ }^{3}$ a scholar of science studies, who looks at the ways scientific discourses limit how a problem can be understood, injury prevention researchers and professional practitioners pursuing engaged scholarship should take a critical look at what biases and frames are taken as givens when formulating a problem. Wynne argues that despite calls for more participation from a wider variety of knowledge holders, the problems we seek answers to are already bounded by the perspectives of expert scientific research and the epistemological commitments of scientific ways of knowing the world. ${ }^{3}$ In this situation, voices from outside of science are easily silenced or dismissed as being too ill-informed to be considered seriously.

Characterising problems in terms of risk is standard practice for injury prevention researchers. For instance, the risk of being injured in a MVC is increased if restraints are not properly used, excessive speed is involved or the driver is intoxicated. In light of this knowledge, researchers go about developing interventions that seek to decrease risks and increase protections in order to reduce MVC injury. The problem with this approach, when striving for engagement, is reflected in Spoel and Den Hoed's critique of community engagement when they write "the risk assessment context indicates the continuing presence of authoritative technical-regulatory framings", which relegates "citizen groups to a downstream, reactive response to a phenomenon already problematized, investigated, and mitigated in terms of 'expert' risk constructs" (p.282). Wynne explains that starting with an issue already defined in terms of risk assumes that people are only concerned with "instrumental consequences, and not also crucially about what human purposes are driving science and innovation in the first place" (p.67). ${ }^{2}$ The notion of an injury being an 'instrumental consequence' is a simplified and not totally fair assessment of how injury prevention research is carried out, but the critique can be applied to much of what goes on in the field because it is calling out the taken-for-granted beliefs and assumptions of how injury prevention research should be done. Further, if researchers are truly invested in engaged research, there is a need for deep reflection on the ways normal science is currently conducted and how it can be changed to open up problem definition to participatory processes by inviting perspectives that are totally unconcerned with the standards of scientific research.

An example that illustrates how injury researchers begin engagement with communities or practitioners with an already narrowed definition of the problem at hand is seen in the Milam et $a l^{5}$ article "Managing conflicts in urban communities: youth 
attitudes regarding gun violence”. Before entering into this critique, it is important to recognise that this study was selected because of its attempt at engagement with affected populations as well as the solid reputation of the researchers that rightfully holds them up as examples of what we are doing well. However, it is also used as an example because it can reveal how research procedures that do engage with community voices can reinforce the marginalised position of the people studied. The method Milam et al used involved identifying specific blocks within an area of Baltimore known to be violent and finding men aged 18 to 24 to complete a hand-written survey called the Survey on Attitudes About Guns and Shootings (SAGAS) that "measure[d] baseline attitudes about the use of guns and violence to resolve disputes" (p.3816). ${ }^{5}$

The researchers predefine the problem in this study as gun violence done by young men. The researchers present the way to mitigate risk as the implementation of the Safe Streets programme that seeks to change attitudes towards gun violence, and success can be measured using the SAGAS. Asking young men, who it is later mentioned are predominantly black, on the streets of Baltimore about their attitudes towards violence may appear to be a form of engagement, but engagement in this way highlights Wynne's point about pre-formed problem definitions and, further, illuminates how unreflexive engagement can serve to reinforce the very social conditions scientists seek to alleviate. Milam and colleagues' research design does ask community members for their opinions; however, these people have been cut-off from the possibility of a full expression of their attitudes about gun violence. The design of this research does not enable a meaningful understanding of the lives this research proclaims it wants to improve because the knowledge that can be shared by participants has been pre-shaped by an expert-created survey before people in the community are brought into the conversation.

More pernicious still is how the racialised nature of the question of gun violence is downplayed in the paper, serving to elude how the design of this research further subjugates, marginalises, dehumanises and fixes in place associations of guns with young black men. Benjamin, ${ }^{6}$ a professor of African American Studies, theorises about how racism is continually reinscribed through science and technology. She writes, "In the post-racial era, subjugation is hardly ever the explicit objective of science and technology; instead, noble aims such as 'health' and 'safety' serve as a kind of moral prophylaxis for newfangled forms of classification and control" (p.150). ${ }^{6}$ Science is only able to deal with existing conceptions of the world, and this case demonstrates how what is already given, in this case, that gun violence is a problem of young black men, is where much research happens. If engaged research is to fulfil its potential of co-creating new possibilities for living, it is necessary to draw out how current research practices are reinforcing harmful conceptions of already marginalised people. More attention should be given to changing research practices that still, perhaps unintentionally, position people as disembodied research subjects.

Breaking open the scientistic frames that bind how injury prevention is conceived helps give import to the notion that science can only analyse existing concepts, and that existing concepts are shaped by subjective, social and political factors. While this is a relatively understood and accepted tenet in research, there is a great deal of action that reflects the belief that science is objective. Given this, there should be more accounting for the consequences of the broader cultural context in which science is conducted. For example, historians of science such as Richardson ${ }^{7}$ illustrate how cultural biases strongly influence and shape scientific knowledge, challenging the objectivist stance sometimes held by those who conduct scientific research. Taking the case of gender bias in science, Richardson analyses the history of how science has reinforced stereotypes of sex difference in the development of genetic theories around the XY and XX chromosomes. In her work, Richardson shows how the 'sex' chromosomes have taken on gendered personalities that are reflective of cultural tropes associated with men and women. Richardson writes, "[ $\mathrm{t}]$ he $\mathrm{X}$ is frequently associated with the mysteriousness and variability of the feminine, as in a 2005 Science article headlined 'She Moves in Mysterious Ways' and beginning, 'The human X chromosome is a study in contradictions"' (p.2). Meanwhile, the Y chromosome is described as macho, active, clever, wily and dominant. ${ }^{7}$

Though there are many examples of how cultural ideology is part and parcel of science, this one example should give injury prevention researchers a place to reflect on how their research is only one of many partial truths. Perhaps looking specifically at how racial, gendered or ageist stereotypes are baked into current evidence is a way to deeply integrate the implications of how science can offer some truths, but truths that are always partial. From this reflection, injury prevention can move on to think about how engaged research could more fully reach its potential of bringing many partial truths together to forge previously unknown connexions and possibilities.

\section{ADDING TO OUR UNDERSTANDING}

A systematic look into the ways engagement is conducted in injury research could give more insight into what is working well and areas in need of improvement. Particularly, getting a feel for how much research is attempting engagement and how that research is conceiving of engagement would be helpful. Another critical question to ask of existing publications is the level to which researchers have approached communities with an open versus predefined field of possibilities about the problem that should be addressed. Interrogating the possibilities for engagement created or constrained by a project's framing can help improve understandings of how prefigured scientific risk constructs shape research/community interactions. Finally, surveying injury researchers about whether and how they account for subjectivity in their work could be fruitful for understanding the underlying logics of the ways research is designed and conducted. Cataloguing injury prevention research's approaches to engagement can provide a picture of the current landscape that can help inform future directions.

\section{RECOMMENDATIONS: ADVICE FOR PRACTITIONERS}

For practitioners who are in contact with communities as well as funding agencies and researchers, there is a need to be explicit about this positioning and clearly present information as the voice of professionals instead of as a representation of community voice. Additionally, practice should seek to develop participatory practices for engagement with communities to enable better cross-sector sharing. Engagement with communities implicitly demands grappling with multiple, marginalised, opposing perspectives and resisting the urge to characterise people as monolithic units with a singular voice that can be located and known. When seeking to be the mediator between communities and researchers, practitioners should be aware of who is and is not heard. With this understanding, professional practitioners should examine the barriers that are keeping some voices on the margins and figure out ways to engage additional perspectives. Further, paying attention to how the information provided by 
community members is assessed and the standards of validity it is being held to is a necessary practice to decentre scientific knowledge as more legitimate than other ways of knowing. Communities may produce uncomfortable, illogical, emotional, non-factual, biased, prejudiced or otherwise distasteful (to you) information. Seeking ways to honour these views is an important capacity-building goal for professional practice.

\section{FUTURE DIRECTIONS: ADVICE FOR RESEARCHERS AND NEXT STEPS}

Going forward, researchers should be more explicit in their goals for engaged research, and I suggest that the goal should be to focus on engagement with the people who will be impacted by a proposed intervention. A more specifically defined understanding of engagement puts professional practitioners and organisational representatives in a different role than they may have played in the past and clearly differentiates practice from community. Researchers have a responsibility to stop conducting research that pretends there is such a thing as a 'community voice'. Additionally, more thought should go into the ways research frames can harmfully position the people that are being engaged. Asking questions about why certain people are selected for input into a particular research question and the potential ways that can serve to reify marginalised positions for those people is vital to doing no harm. Relatedly, research should be open to seeing injury and violence issues as involving more than just risk and the need for strategies that mitigate risk and increase protections. Risk frames limit how problems can be defined and privileges scientific frames that cut off other ways of knowing. This recommendation calls for deep reflection and awareness of the ways disciplinary identities shape our notions of what is the right way to do research. A place to start is to examine reactions to this paper and the logics informing any disagreements you may have with it. Let us commit to open dialogue to explore how engagement could make research processes and findings more relevant and impactful to people's lives.

Acknowledgements I would like to thank Dr. Rod McClure for his visionary leadership, Dr. Myrna Sheldon for her creative and boundary-expanding research, and Dr. Shakiyla Smith for her brilliant mind and loving heart.

Funding The authors have not declared a specific grant for this research from any funding agency in the public, commercial or not-for-profit sectors.

Competing interests None declared.

Patient consent for publication Not required.

Provenance and peer review Commissioned; externally peer reviewed.

\section{REFERENCES}

1 Smith LS, Wilkins N, Marshall SW, et al. The power of academic-practitioner collaboration to enhance science and practice integration: injury and violence prevention case studies. J Public Health Manag Pract 2018;24(Suppl 1):S67-S74.

2 Dempsey SE. NGOs, communicative labor, and the work of grassroots representation. Commun Crit Cult Stud 2009;6:328-45.

3 Wynne B. Risk as globalizing "democratic" discourse? Framing subjects and citizens. In: Leach M, Scoones I, Wynne B, eds. Science and citizens: globalization and the challenge of engagement. London: Zed Books, 2005: 66-82.

4 Spoel P, Den Hoed RC. Places and people: rhetorical constructions of "community" in a Canadian environmental risk assessment. Environ Commun 2014;8:267-85.

5 Milam AJ, Furr-Holden CD, Leaf $P$, et al. Managing conflicts in urban communities: youth attitudes regarding gun violence. J Interpers Violence 2018;33:3815-28.

6 Benjamin R. Catching our breath: critical race STS and the carceral imagination. Engag Sci Technol Soc 2016;2:145-56.

7 Richardson SS. Sex itself: the search for male and female in the human genome. Chicago: University of Chicago Press, 2013: 1-22. 